\title{
Análise Epidemiológica do Câncer de Mama no Estado do Rio de Janeiro nos últimos 5 anos
}

\author{
Epidemiological Analysis of Breast Cancer in the State of Rio de Janeiro in the last 5 years
}

Rafael Spagnol de Almeida ${ }^{1 *}$, Juliana Lopes Dias ${ }^{1}$, Felipe Teixeira Freitas ${ }^{1}$, Bruno Cezario Costa Reis ${ }^{2}$

Como citar esse artigo. Almeida,

R.S.; Dias, J.L.; Freitas, F.T.; Reis,

B.C.C. Análise Epidemiológica do

Câncer de Mama no Estado do Rio de

Janeiro nos últimos 5 anos . Revista de

Saúde 2021 Ago./Nov.; 12 (3): 50-54.

\author{
Resumo
}

O câncer de mama é a neoplasia maligna com maior incidência e letalidade em mulheres no Brasil e no mundo. Possui entre os fatores de risco tanto componentes genéticos quanto ambientais. Portanto, para analisar sua epidemiologia foi realizada uma coleta de dados no Departamento de Informática do Sistema Único de Saúde (DATASUS) e Sistema de Informações Hospitalares do SUS (SIH/SIS) do Ministério da Saúde. O objetivo do presente estudo é analisar o panorama do câncer de mama no Estado do Rio de Janeiro, nos últimos cinco anos, a partir da coleta de dados como internações, óbitos, taxa de mortalidade, faixa etária, sexo, etnia, gasto total e média de permanência hospitalar. Sob essa ótica, as informações, advindas do sistema DATASUS, foram analisadas a fim de concluir se a doença em questão está se encaminhando para um melhor controle no Rio de Janeiro. A partir disso, foi possível concluir que o sexo feminino é o mais afetado, principalmente na faixa etária de 50 a 69 anos. Porém, com maior taxa de mortalidade nos indivíduos com mais de 80 anos e no sexo masculino. Portanto, cabe uma análise mais cuidadosa dessa prevalente patologia, estudando e conscientizando as populações mais vulneráveis sobre seus fatores de risco.

Palavras-chave: Epidemiologia; Neoplasia; Câncer de Mama; Oncologia.

\begin{abstract}
Breast cancer is a malignant neoplasm with the highest incidence and lethality in women in Brazil and most of the world. Has both genetic and environmental components. Therefore, to analyze its epidemiology, a data collection was carried out on Department of Informatics of the Unified Health System (DATASUS) and SUS Hospital Information System (SIH/ SUS) of the Ministry of Health. This study aimed to analyze the breast cancer scenario in the state of Rio de Janeiro, in the last five years, using hospitalizations, deaths, mortality rate, age group, sex, ethnicity and average hospital stay. From this perspective, the information from DATASUS was analyzed in order to conclude if the disease in question is moving towards better control in Rio de Janeiro. From this, it was possible to conclude that the female sex is the most affected mainly in the age groups from 50 to 69 years old, but with a higher mortality rate in those over 80 years old and in the male sex. Therefore, it is necessary to take a more careful analysis of this prevalent pathology, studying and raising awareness among the main vulnerable people about their risk factors.
\end{abstract}

Keywords: Epidemiology; Neoplasm; Breast Cancer; Oncology.

\section{Introdução}

No Brasil, a neoplasia com maior taxa de letalidade em mulheres é a de mama, que tem mostrado uma evolução nos números de casos no país. Estatísticas mundiais do Globocan (Novos Dados Globais Sobre Câncer) 2018, mostram um total de 2,1 milhões de casos novos e 627 mil óbitos pela doença ${ }^{1}$. Uma das explicações para esse aumento seria a maior exposição das pacientes aos fatores de risco que aumentaram devido ao processo de urbanização e mudança do estilo de vida, somado à elevação da expectativa de vida ${ }^{2}$.

Alterações genéticas vêm ganhando espaço nesse cenário e contribuem para esse número, atuando tanto nos cânceres de mama hereditários quanto nos esporádicos. Os hereditários têm como mais comum a presença do gene BRCA1 e BRCA2. Estes últimos possuem a função de fazer a reparação da fita de DNA após a sua quebra e existem algumas etnias que possuem mutações fundadoras nesses genes. Mutações no 
BRCA2 estão relacionadas a neoplasias de receptor de estrogênio positivo e não expressão do receptor HER2, diferente dos que apresentam mutação do BRCA1 e isso interfere no prognóstico, pois pacientes que apresentam receptores positivos possuem um melhor prognóstico em relação às enfermas com receptor negativo. Apesar da diferença, os cânceres de mama relacionados ao BRCA e os esporádicos não possuem divergência nos resultados finais ${ }^{3}$.

A respeito da patogênese da doença, deve-se salientar que todas as neoplasias de mama surgem de uma unidade lobular em um ducto terminal. Porém, o carcinoma invasivo surge de um grupo heterogêneo de lesões e pode ser avaliado de acordo com o grupo histológico ${ }^{3}$. Das lesões, a mais comum é o carcinoma ductal, que corresponde a $80 \%$ dos casos. A segunda mais frequente é o carcinoma lobular presente em 10$20 \%$ das pacientes. Além disso, temos os subtipos, dos quais podemos citar o tubular, mucinoso, medular, papilar, micropapilar e metaplasico, estando presente em cerca de $5 \%$ das lesões ${ }^{3}$.

Os sinais e sintomas da neoplasia de mama são: mudança do tamanho da mama ou de seu contorno, nódulos nos seios, rash na pele ou ao redor do mamilo. Ademais, pode haver ondulações ou enrugamento da pele e inversão do mamilo ${ }^{4}$.

Assim como toda doença, a neoplasia também possui a sua evolução e a sobrevida vai variar de paciente para paciente. No entanto, existem fatores que interferem nessa história natural da doença, dos quais podem ser citados: variação na replicação tumoral, capacidade da doença metastizar, associado a outros fatores ainda desconhecidos ${ }^{5}$.

Quanto ao tratamento, ele se baseia muito na histologia, estágio e biomarcadores. Os estágios da neoplasia se dividem em 0: in situ; 1 e 2: estágio inicial de invasão; 3: invasão local e o 4, que é quando surge a metástase. O carcinoma lobular in situ é o único que não necessita de nenhum tratamento, já o carcinoma ductal in situ é tratado com radioterapia e cirurgia com preservação da mama, sendo que o mesmo é tratado assim devido a sua capacidade de invasão. Tanto os estágios 1 e 2 são tratados com cirurgia conservadora de radioterapia, com o intuito de reduzir a mortalidade e recorrência ${ }^{6}$.

O uso de terapia sistêmica é feito quando ocorre o envolvimento de linfonodo, presença de receptor hormonal, expressão de receptor do HER2, idade da paciente e menopausa. Cânceres com estágio 3, com quimioterapia inicial para diminuição do tamanho do tumor para realizar a cirurgia o mais conservadora possível, mas câncer de mama inflamatório, mesmo no estagio 3, é tratado com quimioterapia e mastectomia radical, retirada de linfonodo axilar e radioterapia. Além disso, o estágio 4 possui o pior prognóstico e, na maioria das vezes, o tratamento passa a ser paliativo ${ }^{6}$.
Portanto, devido a relevância dessa patologia, o objetivo do presente estudo é analisar o panorama do câncer de mama no Estado do Rio de Janeiro, nos últimos cinco anos, a partir da coleta de dados como internações, óbitos, taxa de mortalidade, faixa etária, sexo, etnia, gasto total e média de permanência hospitalar. Sob essa ótica, as informações, advindas do sistema DATASUS, foram analisadas a fim de concluir se a doença em questão está se encaminhando para um melhor controle no Rio de Janeiro.

\section{Material e Métodos}

Foi realizado estudo descritivo, observacional e retrospectivo, através do acesso ao banco de dados de domínio público do Sistema de Informações do Sistema Único de Saúde (SIH/SUS), do Ministério da Saúde, por meio do endereço eletrônico (http://datasus.gov.br), entre os meses de junho e agosto de 2020, referente ao período de registro entre janeiro de 2015 e dezembro de 2019 (Figura 1).

Foram avaliadas as variáveis de internação, óbitos, taxa de mortalidade, faixa etária, sexo, etnia, gasto total e média de permanência hospitalar, disponíveis no DATASUS, referentes ao estado do Rio de Janeiro.

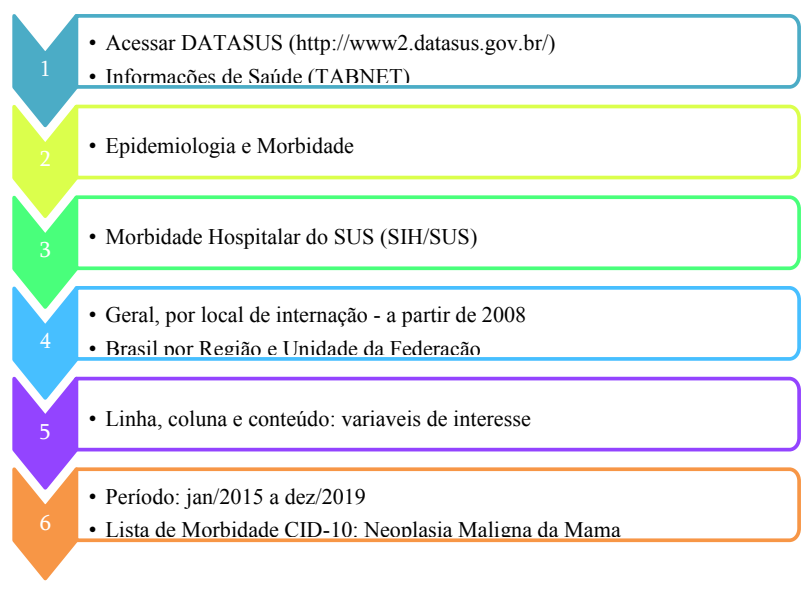

Figura 1. Fluxograma das etapas de acesso ao DATASUS.

\section{Resultados}

De acordo com os dados colhidos no DATASUS, no período analisado, houve 34.198 internações por neoplasia maligna da mama no Estado do Rio de Janeiro. Nesse intervalo de tempo, o ano 2015 foi o de menor número, com 18,13\%, aumentando progressivamente até o ano de 2019, que foi o de maior incidência, com $23 \%$, seguido por 2018 , com $21,21 \%$. Observa-se que apenas esses dois anos foram responsáveis por $44,21 \%$ do total, ou seja, quase metade das internações (Tabela 1). 
Tabela 1. Internações, valor total, média de permanência, óbitos e taxa de mortalidade segundo ano por câncer de mama no Brasil nos últimos cinco anos.

\begin{tabular}{cccccc}
\hline Ano & Internações & $\begin{array}{c}\text { Valor total } \\
(\mathrm{R} \$)\end{array}$ & $\begin{array}{c}\text { Média de } \\
\text { permanência } \\
\text { (dias) }\end{array}$ & $\begin{array}{c}\text { Óbitos } \\
(\mathrm{n})\end{array}$ & $\begin{array}{c}\text { Taxa de } \\
\text { mortalidade } \\
(\%)\end{array}$ \\
\hline 2015 & 6202 & $9.205 .133,15$ & 4,5 & 666 & 10,74 \\
2016 & 6323 & $9.445 .887,39$ & 4,9 & 717 & 11,34 \\
2017 & 6551 & $9.762 .027,16$ & 4,8 & 810 & 12,36 \\
2018 & 7256 & $11.324 .390,80$ & 4,2 & 895 & 12,33 \\
2019 & 7866 & $13.300 .304,80$ & 4,3 & 901 & 11,45 \\
\hline TOTAL & 34198 & $53.037 .743,30$ & 4,5 & 3989 & 11,66 \\
\hline
\end{tabular}

Fonte. SIH/SUS.

O gasto total com a doença nesse intervalo foi de $\mathrm{R} \$ 53.037 .743,30$ (cinquenta e três milhões, trinta e sete mil, setecentos e quarenta e três reais e trinta centavos), tendo seu valor anual crescido de maneira proporcional ao número de internações, sendo 2019 o ano mais dispendioso, com gastos de $\mathrm{R} \$ 13.300 .304,80$ (treze milhões, trezentos mil, trezentos e quatro reais e oitenta centavos) e 2015, o de menor valor gasto, com $\mathrm{R} \$ 9.205 .133,15$ (nove milhões, duzentos e cinco mil, cento e trinta e três reais e quinze centavos) (Tabela 1).

A média de permanência hospitalar, no entanto, variou entre os anos, estando acima da média de 4,5 dias nos anos de 2016 (4,9 dias) e 2017 (4,8 dias) e abaixo dessa mesma média em 2018 (4,2 dias) e 2019 (4,9 dias) (Tabela 1).

O número total de óbitos foi de 3989, demonstrando crescimento ao longo do tempo com o menor quantitativo em 2015 (666), seguido de 2016

Tabela 2. Internações e taxa de mortalidade de acordo com a faixa etária por câncer de mama no Brasil nos últimos cinco anos.

\begin{tabular}{lcc} 
Faixa etária & Internações $(\mathrm{n})$ & Taxa de mortalidade $(\%)$ \\
\hline Menores de 1 ano & 6 & - \\
5 a 9 anos & 1 & 10,00 \\
10 a 14 anos & 10 & 2,94 \\
15 a 19 anos & 68 & 9,84 \\
20 a 29 anos & 386 & 11,26 \\
30 a 19 anos & 2593 & 9,68 \\
40 a 49 anos & 6540 & 10,86 \\
50 a 59 anos & 9806 & 11,63 \\
60 a 69 anos & 8712 & 13,05 \\
70 a 79 anos & 4308 & 21,66 \\
80 anos ou mais & 1768 & 11,66 \\
\hline TOTAL & 34198 & \\
\hline
\end{tabular}

Fonte. SIH/SUS.
(717), 2017 (810) e 2018 (895), até o ano de maior incidência, que foi 2018 (901). Comparativamente, a taxa de mortalidade foi de 11,66 e também demonstrou crescimento ao longo dos anos, estando acima da média em 2016 (11,34), 2017 (12,36), 2018 (12,33) e 2019 $(11,45)$.

Em relação à faixa etária, o maior número de internações foi entre 40 e 79 anos, totalizando $85,87 \%$, com pico entre 50 a 59 anos (9806) e 60 a 69 anos (8712). Dentre os menos acometidos, entre 19 anos ou menos estavam $0,24 \%$; de 20 a 39 anos $8,71 \%$ e nos de 80 anos ou mais houve $5,16 \%$. Em contrapartida, a maior taxa de mortalidade está em uma das faixas menos acometidas, que é a de maiores de 80 anos $(21,66 \%)$, seguido por 70 a 79 anos (13,05\%) e 60 a 69 anos (11,63\%). Além disso, a faixa de 50 a 59 anos, que também é uma das mais acometidas, registrou 10,86. Vale ressaltar que nos indivíduos entre 10 a 14 anos e 20 a 29 anos também foram registradas altas taxas de mortalidade, respectivamente com $10 \%$ e $9,84 \%$ (Tabela 2).

Analisando o sexo, a maior parte das internações é no feminino, com 99,16\% (33.911), com 3945 óbitos e taxa de mortalidade de 11,63. Porém, apesar do masculino ter apenas $0,83 \%$ (287) das hospitalizações, o número de óbitos foi de 44, fazendo com que, proporcionalmente, a taxa de mortalidade se tornasse maior, com $15,33 \%$.

Em relação à etnia, o maior número foi dos brancos $(36,47 \%)$, seguidos dos pardos $(34,25 \%)$, negros $(14,41 \%)$, amarelos $(2,36 \%)$ e indígenas $(0,014 \%)$. No que diz respeito à taxa de mortalidade, a maior foi entre os negros $(13,47)$, seguidos dos brancos $(12,03)$, pardos $(11,55)$, amarelos $(9,15)$ e nula nos indígenas. No entanto, é importante ressaltar que 4.266, ou seja, $12,47 \%$ dos prontuários não constavam informações sobre cor/raça (Tabela 3).

Em relação aos municípios fluminenses, a cidade do Rio de Janeiro tem a grande maioria dos casos, com $70,89 \%$, em seguida estão Campos dos Goytacazes, Cabo Frio e Volta Redonda, que, juntas, somaram 13,69\%. No entanto, é importante evidenciar que parte das cidades que registraram poucos casos apresentam altas taxas de 
Tabela 3. Internações e taxa de mortalidade segundo etnia por câncer de mama no Brasil nos últimos cinco anos.

\begin{tabular}{lcc} 
Cor/raça & Internações (n) & Taxa de mortalidade (\%) \\
\hline Branca & 12474 & 12,03 \\
Negra & 4929 & 13,47 \\
Parda & 11715 & 11,55 \\
Amarela & 809 & 9,15 \\
Indígena & 5 & - \\
Sem informação & 4266 & 9,33 \\
\hline TOTAL & 34198 & 11,66 \\
\hline
\end{tabular}

Fonte. SIH/SUS

mortalidade, sendo elas: Angra dos Reis (50\%), Armação dos Búzios (50\%), Arraial do Cabo (55,56\%) Belfrod Roxo (100\%), Casimiro de Abreu (50\%), Conceição de Macabu (100\%), Guapimirim (100\%), Itaboraí (50\%), Mendes (50\%), Miracema (55,56\%), Paracambi (50\%), Paraty (77,78\%), Pinheiral (50\%), Rio das Flores (100\%), São Francisco de Itabapoana (50\%), São José do Vale do Rio Preto (100\%), Saquarema (100\%) e Três Rios (50\%).

\section{Discussão}

De acordo com os dados obtidos, a partir da análise do período de cinco anos, o câncer de mama esteve com seus números em ascensão no que tange às internações e à taxa de mortalidade. Corroborando esses dados, segundo o Instituto Nacional do Câncer (INCA), o câncer de mama em indivíduos do sexo feminino foi o que apresentou maior incidência no Brasil, no ano de 2020, com 66.280 casos novos. Em contrapartida, apenas $1 \%$ dos casos é do sexo masculino, com 17.575 mortes em mulheres e 189 em homens, no ano de $2018^{8,9}$.

Justificando esse aumento, que está acontecendo apesar da evolução nos métodos diagnósticos e de tratamento, dados mundiais indicam que apenas 5\% a $10 \%$ do total de casos dessa neoplasia são por causas genéticas/hereditárias. Ou seja, causas ambientais, em alta no período atual, são as mais prevalentes ${ }^{7}$. Além disso, a evolução nos métodos de diagnóstico, principalmente devido à instauração do rastreamento, contribui para o aumento da notificação de casos, uma vez que, segundo a Sociedade Brasileira de Oncologia, entre 2010 e 2015, o número de mamografias ofertadas pelo SUS aumentou $31 \%$ no total, no primeiro semestre e $51 \%$ entre mulheres de 50 a 69 anos $^{10-12}$.

Sendo assim, vale ressaltar que o principal fator de risco para a doença é a idade maior que 50 anos. Porém, há outros fatores importantes, como mulheres nulíparas, baixo número de gestações, primigesta de idade avançada, uso de contraceptivos orais, histórico familiar de câncer de mama e ovário, alterações genéticas nos genes BRCA1 e BRCa2 $2^{2,7}$. Além disso, fatores comportamentais também podem ser citados, como obesidade e sobrepeso após a menopausa, sedentarismo, consumo de álcool e exposição frequente à radiação ionizante ${ }^{2,7}$.

Os dados obtidos correspondem com os dados da literatura, com pico no número de internações entre $50 \mathrm{e}$ 69 anos, apesar de uma maior taxa de mortalidade a partir de 80 anos. No entanto, apesar de ser bem elucidado que a idade contribui para o desenvolvimento do câncer de mama, outros estudos apresentam dados conflitantes ao indicarem que para casos já diagnosticados, a taxa de mortalidade praticamente não varia entre mulheres mais jovens em comparação às mais velhas ${ }^{13,14}$. Sendo assim, a prevenção secundária recomendada pelo Ministério da Saúde continua sendo a mamografia, que deve ser realizada entre 50 e 69 anos, a cada dois anos; enquanto a primária consiste em evitar os fatores de risco ${ }^{15,16}$.

Sabe-se, de acordo com os dados apresentados, que a neoplasia maligna da mama acomete mais o sexo feminino, no entanto, tende a ser mais agressiva no masculino, apresentando menos de $1 \%$ das internações e alta taxa de mortalidade (15,33\%). Elucidando esse fato, de acordo com dados da pesquisa nacional por amostra de domicílios (PNAD), entre 20 e 64 anos, 20,8\% dos homens não estiveram em contato com serviços de saúde no último ano, contra 10,1\% das mulheres, enquanto apenas $1,8 \%$ dos homens relata ter feito pelo menos uma consulta nesse período, contra 3,9\% das mulheres. Sendo assim, a busca tardia por atendimento resulta em piores prognósticos, com maior morbidade, maior mortalidade e necessidade de tratamentos mais $\operatorname{agressivos}^{17}$.

De acordo com dados do DATASUS, a incidência de casos é maior na etnia branca, seguida pela parda. Todavia, os estudos relacionados a essa variável, tanto em análise quanto em interpretação, são escassos quando comparados a países desenvolvidos ${ }^{18}$. O que comprova esse fato é que somente a partir do ano 2000 o Ministério da Saúde introduziu esse dado na coleta de informações do paciente, a fim de identificar as diferenças. Contudo, ainda carece de maior atenção dos profissionais de saúde, tendo em vista que $12,47 \%$ dos prontuários não continham essa informação no período de 2015 a $2019^{19,20}$.

Sabe-se que quanto mais cedo a neoplasia é detectada, maior a probabilidade de cura, inclusive com uma terapêutica menos invasiva. No entanto, apesar do avanço dos métodos, ainda há grande disparidade global, fazendo com que devido ao déficit de conhecimento a respeito da doença e dificuldade de acesso, muitas mulheres procurem os serviços de saúde já em estágios avançados $^{1}$. Esse fato é uma das maneiras de explicar o motivo pelo qual alguns municípios, principalmente do interior do estado, apresentam poucos casos, mas 
taxas de mortalidade a partir de $50 \%$, ou seja, nessas cidades, metade ou mais dos pacientes acometidos evoluem para óbito pelo câncer de mama. Isso se deve a essa disparidade evidenciada, em que as cidades mais pobres, por não apresentarem métodos tão modernos de diagnóstico e tratamento, acabam com um descobrimento tardio e, consequentemente, um pior prognóstico das pacientes.

\section{Conclusão}

Sendo assim, de acordo com os dados e fontes analisadas, pode-se concluir que o câncer de mama tem altas incidência e taxa de mortalidade no Estado do Rio de Janeiro e que, infelizmente, ainda falta muito para que a doença deixe de ser um problema de saúde pública que afeta e leva a óbito muitas mulheres.

Confirmando os dados existentes na literatura, a faixa etária mais afetada foi a de 50 a 69 anos. Entretanto, apesar da alta taxa de mortalidade desde essa faixa, o pico foi entre os maiores de 80 anos.

Em relação ao sexo, o mais afetado é, sabidamente, o feminino. Porém, o masculino demonstrou maior taxa de mortalidade e, em última análise, a etnia mais afetada foi a branca.

Nesse sentido, é possível afirmar que o câncer de mama é um problema de saúde pública no Brasil e no mundo, porque, embora haja meios para melhora, continua com altas taxas de mortalidade, principalmente devido à falta de informação em alguns locais, o que leva ao diagnóstico tardio.

Portanto, é necessário que uma análise criteriosa seja feita a respeito dos locais onde as populações são mais vulnerável e devem ser melhor conscientizadas. Para isso, os agentes comunitários de saúde podem contribuir com a comunicação nas visitas domiciliares. Por fim, é preciso que se melhore a cobrança por um correto e completo preenchimento dos prontuários de saúde, a fim de possibilitar estudos epidemiológicos mais abrangentes, que contribuirão para a saúde do país.

\section{Referências}

1. A Situação do Câncer de Mama do Brasil: Síntese de Dados dos Sistemas de Informação. [ebook]. 2019 Disponível em: https://www.inca.gov.br/sites/ ufu.sti.inca.local/files/media/document/a_situacao_ca_mama_brasil_2019. pdf; Acesso em: 29 de agosto de 2020.

2. Migowski A, Silva GA, Dias MBK, Diz MDPE, Sant'Ana DR, Nadanovsky P. Diretrizes para detecção precoce do câncer de mama no Brasil. II - Novas recomendações nacionais, principais evidências e controvérsias. Cad. Saúde Pública 2018; 34(6):e00074817.

3. Libson S, Lippman M. A Review of Clinical Aspects of Breast Cancer. Int Rev Psy. 2014; 26 (1):4-15.
4. Pearce, L. Breast Cancer. Nurs Stand. 2016; 30(51): 15.

5. Sartori ACN, Basso CS. Câncer de Mama: Uma Breve Revisão de Literatura. Perspectiva, 2019;43(161):07-13.

6. Maughan KL, Lutterbie MA, Ham PS. Treatment of breast cancer. Am Fam Physician. 2010;81(11):1339-1346;

7. DATASUS (SIH-SUS) - avaliado de jan de 2010 a dez de 2019, avaliando internações, taxa de mortalidade, sexo e faixa etária. Acesso em 29 de agosto de 2020.

8. INCA - Instituto Nacional de Câncer. Estatísticas de câncer. 2020. Disponível em: https://www.inca.gov.br/numeros-de-cancer. Acesso em 29 de agosto de 2020

9. Instituto Oncoguia. Brasil deve ter aumento de $42 \%$ nos casos de câncer na próxima década, diz estudo. 2020. Disponível em: http://www.oncoguia. org.br/conteudo/brasil-deve-ter-aumento-de-42-nos-casos-de-cancer-naproxima-decada-diz-estudo/13862/42/; Acesso em 29 de agosto de 2020

10.- Sociedade Brasileira de Oncologia Clínica. Brasil avança no diagnóstico do câncer de mama. 2015. Disponível em: https://www.sboc.org.br/noticias/ item/253-brasil-avanca-no-diagnostico-do-cancer-de-mama. Acesso em 29 de agosto de 2020 .

11. Rodrigues JD, Cruz MS, Paixão AN. Uma análise da prevenção do câncer de mama no Brasil.Ciênc Saúde Colet. 2015;20 (10):3163-3176.

12. Martins E, Freitas-Junior R, Curado MP, Freitas NMA, de-Oliveira JC, Silva CMB. Evolução Temporal dos Estádios do Câncer de Mama ao Diagnóstico em um Registro de Base Populacional no Brasil Central. Rev Bras Ginecol Obstet. 2006; 31(5):219-223.

13. Ferras RO, Moreira-Filho DC. Análise de Sobrevivência de Mulheres com Câncer de Mama: Modelos de Riscos Competitivos. Ciênc Saúde Colet. 2017;22(11):3743-3753.

14. Cai M, Wei J, Zhang Z, Zhao H, Qiu Y, Fang Y, et al. Impact of Age on the Cancer-Specific Survival of Patients with Localized Renal Cell Carcinoma: Martingale Residual and Competing Risks Analysis. Plos One. 2012;7(10):1-7.

15. INCA - Instituto Nacional de Câncer. Câncer de mama. Disponível em: https://www.inca.gov.br/tipos-de-cancer/cancer-de-mama. Acesso em 29 de agosto de 2020 .

16. Kolak A, Kamińska M, Sygit K, Budny A, Surdyka D, Budny BK, et al. Primary and secondary prevention of breast cancer. Ann Agric Environ Med. 2017;24(4):549-553

17. da-Silva JFC, Marques EM, da-Silva RD, Correia ADN, Santos RFS, dos-Santos WS. Mortalidade por Câncer de Mama Masculino nas Regiões Brasileiras e nos Estados do Nordeste. Saúde (Santa Maria). 2020;46(2):e39396.

18. Travassos C, Williams DR. The concept and measurement of race and their relationship to public health; a review focused on Brazil and United States. Cad Saude Publica. 2004; 20(3):660-678.

19. Fundação Nacional de Saúde. Saúde da População Negra no Brasil. Brasília: Ministério da Saúde. [ebook]. 2005. Disponível em: http://bvsms. saude.gov.br/bvs/pop_negra/pdf/saudepopneg.pdf; Acesso em 29 de agosto de 2020 .

20. Chor D, Lima CRA. Aspectos Epidemiológicos das Desigualdades Raciais em Saúde no Brasil. Cad Saúde Pública. 2005;21(5):1586-1594. 